\title{
Copa do Mundo e cerveja: impactos intangíveis de um megaevento
}

\author{
Liana Abrão Romera*
}

\begin{abstract}
Resumo: A realização de megaeventos esportivos no Brasil tem motivado mudanças em vários âmbitos sociais, além de promover alterações na legislação. As exigências da Federação Internacional de Futebol Association (FIFA) desconsideram conquistas referentes às políticas do álcool e sobre violência nos estadios, estreitando o vínculo entre cerveja e futebol. Considerando as consequências negativas da concessão da venda e consumo de cerveja nos estádios e a publicidade de cerveja envolvendo a Copa do Mundo, este artigo discute impactos intangíveis da Copa do Mundo de 2014. Sinaliza aumento do numero de consumidores de cerveja em conseqüência da Lei Geral da Copa, ressaltando os aspectos negativos para a sociedade.
\end{abstract}

Palavras-chave: megaevento; copa do mundo; cerveja.

Desde a realização dos Jogos Pan-Americanos de 2007, sediados na cidade do Rio de Janeiro, o Brasil já foi palco dos Jogos Militares em 2011, da Copa das Confederações 2013, e ainda sediará a Copa do Mundo de Futebol FIFA 2014, a Copa América de 2015 e os Jogos Olímpicos de 2016, também no Rio de Janeiro.

Trata-se de uma realidade sobre a qual não cabe uma expressão contrária à realização desses megaeventos, mas é legítimo o posicionamento crítico expressado por meio de alertas acerca das consequências diretas ou indiretas de megaeventos.

Para tratar da temática dos megaeventos esportivos, Da Costa (2008), Mascarenhas (2012), Proni (2009), Raeder (2010), Reppold Filho (2008), Tavares (2011), entre outros, realizaram investigações com foco no legado referente ao meio urbanístico, ordenamento 
territorial, ocupação dos espaços públicos, construção e animação de equipamentos esportivos, transportes, serviços e políticas de esporte.

Ao questionar o papel das Ciências do Esporte ante o panorama dos megaeventos, porém com destaque para os Jogos Olímpicos, Mascarenhas (2012, p. 62) faz importantes provocações:

Isto significa problematizar não só o seu impacto [Jogos Olímpicos] ou relações com a escola, mas também com as práticas corporais e a saúde, o meio ambiente, a comunicação e a mídia, o corpo e a cultura, a formação profissional, os movimentos sociais, as políticas públicas, a inclusão e a diferença, o próprio desempenho e treinamento etc.

Essa a problematização ultrapassa as barreiras do tangível, do material, e requer mais que a preocupação direcionada a construções e equipamentos esportivos e questiona a relação que eventos de tal magnitude estabelecem com o campo de conhecimento da Educação Física e com a sociedade.

Discutir os impactos de um determinado megaevento compreende contemplar suas influências em diferentes segmentos sociais com base em um exercício interdisciplinar, abarcando interferências produzidas na educação, saúde, comunicação, modos de consumo, políticas públicas, entre outras.

Considerando as influências dos megaeventos na legislação interna do Brasil, Reis (2012) apresenta um estudo sobre a proposição legislativa (PL) n. 2.330/2011, que fora transformada na Lei Ordinária (LO) n. 12.663/2012, cujo conteúdo dispõe sobre as medidas relativas à Copa das Confederações em 2013 e à Copa do Mundo em 2014, sediadas no Brasil. A autora desenvolve uma análise do documento e da construção da legislação sobre violência e prevenção em espetáculos esportivos e adverte: "É tarefa da academia brasileira, considerada como parte importante da sociedade civil, contribuir com suas investigações e produções para que as ameaças não se tornem realidade e para que a sociedade

Movimento, Porto Alegre, v. 20, n. 2, p. 775-798, abr./jun. de 2014. 
Copa do Mundo e cerveja: impactos intangíveis..

brasileira não venha a ter mais prejuízos com a promoção destes eventos" (REIS, 2012, p. 79).

Embora haja uma lista de eventos esportivos internacionais que o Brasil sediará nos próximos anos, este artigo ficará restrito a questões afeitas à Copa do Mundo de Futebol de 2014, especialmente pela direta associação que se estabeleceu entre bebida alcoólica, futebol e Copa do Mundo.

Diante de determinadas situações que compõem o quadro atual, o presente artigo tem por objetivo discutir impactos intangíveis da Copa do Mundo de Futebol de 2014 e ressaltar alguns desdobramentos promovidos pela liberação da venda e consumo de cerveja nos estádios de futebol durante a ocorrência de megaeventos esportivos.

A proibição da comercialização e consumo de cerveja nos estádios de futebol no Brasil está regulamentada por leis estaduais e municipais. No estado de São Paulo, essa proibição vigora na Lei Estadual n. 9.470, de 27 de dezembro de 1996, Artigo 5º Inciso 1. Já na cidade de São Paulo, na Lei Municipal n. 14.726, de 15 de maio de 2008. No estado de Pernambuco, na Lei Ordinária n. 13.748/2009. No estado do Rio de Janeiro, na Lei Estadual n. 2.991/1998.

Considerando que a violência e o consumo exagerado de bebidas alcoólicas são questões sociais produzidas pela interseção de inúmeros e diferentes fatores, há que se levar em conta que entre os motivos que culminaram na proposição e implementação dessas referidas leis tiveram por objetivo a diminuição de cenas de violência em que tais estados e municípios eram recorrentemente palco de cenas lastimáveis envolvendo torcedores e violência.

Sem perder de vista a complexidade que essa temática envolve, e entendendo que esta não pode ser discutida de forma simplista ou conduzida por um olhar unicausal, corrobora-se aqui as considerações de Reis.

Sem dúvida, reduzir as raízes e causas da violência ao consumo de bebida alcóolica é um reducionismo inaceitável e uma explicação sociológica

Movimento, Porto Alegre, v. 20, n. 2, p. 775-798, abr.jun. de 2014. 
inconsistente. No entanto, compreendendo a problemática da violência em torno do futebol, principalmente aquelas manifestadas nas grandes cidades em dias de jogos de futebol profissional entre equipes arquirrivais como um problema complexo e multifatorial, pode-se sim incluir entre os fatores geradores de violência o uso abusivo de álcool pelos jovens espectadores de futebol (REIS, 2012, p. 80).

A flexibilização da venda e consumo de bebidas alcoólicas no interior dos estádios representa uma exigência da Federation International Football Associations (FIFA) - que fora prontamente atendida pelo Estado brasileiro -, desconsiderando assim a implementação de políticas do álcool e de prevenção à violência nos estádios de futebol. A flexibilização das normas internas referentes à comercialização e consumo de cerveja nos estádios de futebol também expressa a desconsideração às leis estaduais e municipais do país em favor do lucro de uma cervejaria internacional patrocinadora da FIFA e de determinada cervejaria nacional, que por sua vez patrocina a seleção brasileira de futebol. Ainda que pese a decisão final sobre a venda de bebidas nos estados e municípios nos quais vigora legislação regulamentando o comércio e consumo de cerveja nos estádios aos seus respectivos governantes, abrem-se, em nome dos megaeventos, precedentes que exercerão fortes influências sobre decisões políticas que serão tomadas durante os jogos da Copa do Mundo - com possibilidades de se perpetuarem posteriormente.

Se o fortalecimento da cultura do beber é também embalado por uma intensa publicidade, que tem nos astros do futebol brasileiro os seus principais garotos-propaganda, num exercício incansável de aproximação do futebol com o consumo de cerveja, tal estímulo não faltará em tempos de Copa do Mundo. A relação entre futebol e cerveja, já bastante explorada pela indústria do marketing no Brasil, conforme denunciam Bertolo e Romera (2011), Pinsky (2009), Pinsky e Jundi (2008), terá a chance de ocorrer de forma ainda mais intensa no período que antecede e durante as transmissões da Copa do Mundo.

Movimento, Porto Alegre, v. 20, n. 2, p. 775-798, abr./jun. de 2014. 
Questiona-se quais os impactos sociais e imateriais que a Copa de Futebol deixará para o Brasil e para os torcedores brasileiros. A flexibilização para o comércio e consumo de cervejas nos estádios configura o estado de exceção somente restrito à Copa do Mundo (recentemente extensivo à Copa das Confederações)? Ou o precedente aberto antecipará oportunidade de comércio e venda de bebidas nos estádios, a começar com os campeonatos estaduais e nacionais, estendendo-se tal liberação para antes e depois de 2014?

As respostas para essas questões já foram dadas por meio da Resolução da Presidência da Federação de Futebol do Rio de Janeiro (RDP) n. 12/2013, emitida em $1^{\circ}$ de março de 2013 pelo presidente da Federação de Futebol do Estado do Rio de Janeiro, Rubens Lopes da Costa Filho, que resolve sobre a liberação da venda e consumo de bebidas durante o campeonato carioca, conforme a decisão da referida instituição. Em seu documento, entre os inúmeros argumentos apresentados, Costa valeu-se, de antemão, da concessão feita à FIFA por ocasião da Copa do Mundo de 2014:

Considerando que a própria FIFA, entidade máxima do futebol mundial, autoriza a comercialização de cervejas no interior dos estádios durante as principais competições de futebol existentes (a Copa das Confederações e a Copa do Mundo FIFA), que serão disputadas no Brasil em 2013 e 2014, respectivamente.

Os precedentes e as concessões abertos em favor da FIFA e da Copa do Mundo, aqui compreendidos como impactos intangíveis antecipados, dão margem a outro questionamento. Ao término da Copa de Futebol de 2014, retornarão as leis municipais e estaduais anteriormente vigentes, ou a parcela da sociedade atenta ${ }^{1}$ às questões do consumo de bebidas alcoólicas nos estádios terá que iniciar uma nova e exaustiva batalha para a reconquista e validação

\footnotetext{
${ }^{1}$ Referência aos grupos sociais formados por pesquisadores da área da Saúde, da Violência, da Segurança, entre outras, mas com destaque para os pesquisadores da área da Saúde que elaboraram a Lei do Álcool (LARANJEIRA; ROMANO, 2004) e comissões que discutem o Estatuto do torcedor e a segurança nos estádios de futebol.
}

Movimento, Porto Alegre, v. 20, n. 2, p. 775-798, abr.jun. de 2014. 
de políticas do álcool, de prevenção da violência, anteriormente implementadas?

\section{Megaeventos esportivos, Legados e impactos}

Os termos megaevento e legado representam tema importante e cada vez mais constantes nas pesquisas científicas e também observados nos noticiários midiáticos com a mesma intensidade $\mathrm{e}$ falta de exatidão.

Tavares destaca: "megaeventos sãomelhor[sic] compreendidos como eventos culturais (inclusive comerciais e esportivos) de larga escala, os quais têm um caráter dramático, apelo popular de massa e significado internacional" (HORNE; MANZENREITER, 2006, p. 2 apud TAVARES, 2011, p. 17).

Hall apresenta outra interface marcada pelos interesses econômicos que permeiam os megaeventos: “[...] grandiosidade em termos de público, mercado-alvo, nível de envolvimento financeiro do setor público, efeitos políticos, extensão de cobertura televisiva, construção de instalações e impacto sobre o sistema econômico e social da sociedade anfitriã" (HALL, 2006, p. 59 apud TAVARES, 2011, p. 17).

O termo legado também acompanha as discussões dos megaeventos, sendo apresentado com duas categorias que possibilitam considerar questões materiais e imateriais propiciadas por esses acontecimentos:

[...] pode ser considerado como legado tangível toda a infra-estrutura construída por causa do megaevento e não apenas aquela diretamente relacionada à sua realização, pois ela é suscetível à análise econômica de custo-benefício. Já o impacto cultural do megaevento pode ser considerado como um legado intangível, pois seus efeitos repercutem sobre a autoimagem do lugar e seus habitantes, as atitudes, a identidade projetada e outros aspectos sócioculturais cuja mensuração exata é mais duvidosa. (POYNTER, 2006 apud TAVARES, 2011, p. 33).

Movimento, Porto Alegre, v. 20, n. 2, p. 775-798, abr./jun. de 2014. 
A palavra legado causa a impressão de que algo positivo será deixado para a população, uma espécie de presente que será transformado em propriedade dos cidadãos locais, que poderão então tomá-lo para si, incorporá-lo ao cotidiano e dele usufruir.

Na maioria das vezes, a menção ao legado remete à ideia do tangível, do material, do concreto, pois ele se encontra estreitamente relacionado às instalações esportivas, parques, praças, estádios, melhoria do transporte urbano e outros serviços que o Estado promete aprimorar em virtude do megaevento.

Ultrapassando a classificação de tangível e intangível, Preuss (2007) estabeleceu uma distinção entre "legados" e "impactos" de megaeventos de modo que acomodasse a previsão de possíveis efeitos negativos promovidos por esses acontecimentos. Nesse sentido, os impactos encontram-se mais próximos das consequências negativas.

Assim, os impactos intangíveis provocados pela Copa do Mundo de Futebol de 2014 e legitimadas pela Lei Geral da Copa resultam da prevalência de interesses de grandes corporações comerciais em detrimento de políticas públicas, de campanhas para redução do consumo de álcool, entre outros.

Para discutir a organização dos espetáculos esportivos e seus impactos na Lei Geral da Copa, Reis (2012, p. 3) ressalta posicionamento defendido por Rolnik, que denuncia o estado de exceção criado em consequência dos megaeventos:

Ocorre uma espécie de suspensão da ordem pública vigente na cidade e uma introdução de outra ordem que domina e define as regras do espaço público. Copa do Mundo e Olimpíadas são eventos semelhantes, mas na Copa esse processo se dá de forma muito mais radical, pois no protocolo geral se estabelece um rol de novas regras que se sobrepõem às regras do país tal como um estado de exceção, como se estivéssemos em uma guerra.

Movimento, Porto Alegre, v. 20, n. 2, p. 775-798, abr.jun. de 2014. 
O estado de exceção é descrito por Agamben (2004) como um novo paradigma de governo cuja finalidade é dar legalidade àquilo que não pode ter forma legal. Afirma o autor tratar-se da suspensão de normas constitucionais para a implantação de uma nova ordem jurídica.

Agamben (2004) adverte que aquilo que inicialmente era para ser um estado provisório termina como estado permanente, suspende a ordem jurídica, incorpora-se ao cotidiano e gradativamente se transforma em permanente, fazendo com que a exceção se torne regra.

Ao se observar as exigências da FIFA ao Estado brasileiro e suas interferências exercidas sobre a Lei Geral da Copa, evidenciam-se interesses comerciais, entre eles, de modo especial, o aumento da venda de cerveja.

Trata-se, portanto, de um dos grandes impactos intangíveis promovidos pela Copa do Mundo de 2014, ao flexibilizar a legislação sobre a venda e consumo de cerveja nos estádios de futebol, confirmando-se um estado de exceção que, conforme denuncia Agamben, de provisório passará a permanente.

Caso o referido megaevento, como estande de venda de marcas, estivesse restrito, por exemplo, a propagandas de materiais esportivos, possivelmente os impactos intangíveis daí advindos pudessem ser menores, menos danosos à sociedade. No entanto, é sabido que entre os principais produtos, se não o principal, vinculados à Copa do Mundo da FIFA está a cerveja, artigo nem tão neutro ou inofensivo como querem supor os representantes da entidade, do governo ou da publicidade.

Em nome do lucro, a intangibilidade não está somente na imposição da flexibilização de leis ao país, mas também no produto a ser propagandeado e consumido, o álcool, que, como afirmam Laranjeira e Romano (2004, p. 69), não é um produto qualquer. Os pesquisadores chamam a atenção para a maneira como as bebidas são divulgadas e comercializadas no país:

Movimento, Porto Alegre, v. 20, n. 2, p. 775-798, abr./jun. de 2014. 
A despeito de todos os significados culturais e simbólicos que o consumo de bebidas alcoólicas adquiriu ao longo da história humana, o álcool não é um produto qualquer. [...] seus danos podem ser agudos ou crônicos e dependem do padrão de consumo de cada pessoa, que se caracteriza não somente pela freqüência com que se bebe e pela quantidade por episódio, mas também pelo tempo entre um episódio e outro e ainda pelo contexto em que se bebe.

Não se trata de demonizar o álcool e responsabilizar unicamente o consumo de bebidas por situações de violência, brigas nos estádios e demais confusões e atritos promovidos por torcedores, pois tal relação representa um fenômeno polissêmico e complexo. Minayo e Deslandes (1998) analisaram as possíveis relações estabelecidas entre violência, drogas e álcool na literatura científica nacional e internacional e reconheceram a complexidade que permeia tal associação.

Parte do estudo das autoras refere-se à análise de atendimentos realizados em dois importantes hospitais do Rio de Janeiro quando esses envolviam a ocorrência de violência Quando verificado com os profissionais da saúde se o evento atendido envolvia o uso de algum tipo de droga, encontraram que "Nos casos em que foi identificado o consumo de algum tipo de droga, o álcool configurouse como o mais frequentemente consumido: $88 \%$ (HMSF) e $90,7 \%$ (HMMC)" (MINAYO; DESLANDES, 1998, p. 36).

Muito embora o consumo de bebidas tenha sido verificado em altas porcentagens entre as vítimas e agressores, é reconhecida a dificuldade de isolar o consumo de bebidas dos demais fatores da vida que pudessem influenciar nos episódios marcados pela violência.

Minayo e Deslandes (1998, p. 37) ainda destacam que "Enquanto os especialistas concordam que as drogas frequentemente têm papel importante nas atividades violentas, seu papel específico não está claro, ou seja, é difícil determinar com precisão o nexo

Movimento, Porto Alegre, v. 20, n. 2, p. 775-798, abr.jun. de 2014. 
causal entre essas substâncias e atos violentos". No entanto, as autoras destacam conclusões de estudos que revelam ser o álcool a substância mais ligada às mudanças de comportamento provocadas por efeitos psicofarmacológicos que têm como resultado a violência. "Embora todas as evidências empíricas revelem que é o álcool a substância mais significativa na articulação com várias formas de violência, seu status de legalidade torna-o socialmente aceito e largamente consumido, ainda que se tente regular seu uso" (MINAYO; DESLANDES, 1998, p. 38).

Incorrer no estabelecimento de uma relação simplista entre violência e consumo de bebidas representa equívoco para o qual os estudos de Minayo e Deslandes (1998), Romera (2008), Romera e Reis (2009) têm alertado, reafirmando que tal relação não é unicausal. No entanto, faz-se urgente:

1- Reconhecer o estado de exceção imposto pela FIFA para legitimar seus interesses econômicos em detrimento das políticas de saúde e de prevenção;

2- Ressaltar a desconsideração ao esforço acumulado em pesquisas, discussões e conquistas acerca dos problemas referentes à violência e ao consumo de bebidas realizado até o momento;

3- Destacar a suspensão de políticas do álcool em vigência nos estádios de futebol de alguns estados do país.

Arestrição ao consumo e venda de bebidas alcoólicas no interior dos estádios de futebol constitui uma diretriz de segurança que fora adotada por meio de ação conjunta e coordenada pelos Ministérios Públicos Estaduais, por intermédio do Protocolo de Intenções celebrado entre o CNPG (Conselho nacional de procuradores gerais) do Ministério Público dos Estados e da União e a Confederação Brasileira de Futebol (CBF), na data de 25 de abril de 2008.

Ao se considerar as interferências que o consumo de álcool pode provocar no comportamento do indivíduo e no social, e ter em conta que não se trata de um produto qualquer, faz-se importante

Movimento, Porto Alegre, v. 20, n. 2, p. 775-798, abr./jun. de 2014. 
lembrar que na classificação das substâncias o álcool é considerado uma droga, ainda que lícita.

\section{Drogas, Álcool e ConTRAdições dA MídiA}

As preocupações midiáticas e sociais voltam-se para os impactos negativos provocados pelas drogas ilícitas (cocaína, crack, ecstasy, maconha). De modo geral, a ênfase dos programas televisivos recai sobre os usos e usuários de substâncias ilícitas, fazendo parecer que estes representam maior contingente de pessoas, se comparados àqueles formados por consumidores de drogas lícitas (tabaco, álcool, remédios).

Os dados levantados pela Secretaria Nacional Antidrogas (SENAD) e pela Associação Brasileira de Estudos de Álcool e Drogas confrontam a ideia que a mídia veicula acerca do lícito e ilícito, pois demonstram que mais da metade da população brasileira adulta (52\%) consome bebidas alcoólicas, e somente $3 \%$ da população é composta por usuários de maconha, e 2\% de usuários de cocaína, ou seja, o enfoque dado à temática das drogas deveria voltar-se para o consumo de álcool, que é formado por um público imensamente maior que aquele que consome drogas ilícitas.

As informações veiculadas nos canais de televisão contribuem para a impressão de que somente o uso de substâncias ilícitas causa danos à saúde e à sociedade, promovendo um desvio da atenção aos impactos (muito maiores) gerados pelo consumo de drogas de uso legalizado - que, por sua vez, são grandes patrocinadores dos programas televisivos.

Nesse sentido, as políticas sobre drogas devem focar a atenção para o lícito, que abarca um maior contingente de consumidores, esforço que já vinha sendo realizado por intermédio das políticas do álcool.

Atualmente, a postura social frente ao uso de bebidas alcoólicas e outras drogas é marcada pela contradição do lícito e do ilícito, bem como pela diversidade de opiniões a respeito dos danos,

Movimento, Porto Alegre, v. 20, n. 2, p. 775-798, abr.jun. de 2014. 
benefícios, prazer e desprazer. Os meios de comunicação acompanham e fortalecem essas contradições. De um lado, a população recebe uma série de informações sobre a violência relacionada ao tráfico e sobre os "perigos das drogas" e, por outro lado, é alvo de sofisticadas propagandas para estímulo da venda de bebidas alcoólicas. Nesse contexto, esses grupos de "drogas" semelhantes em vários aspectos farmacológicos passam a ser encarados tão distintamente na opinião pública, o que gera posturas extremamente incoerentes sob a ótica da saúde (NOTO; BAUER, 2011, p. 1).

Na forma de notícia ou publicidade, os meios de comunicação são importantes instrumentos na divulgação de informação que contribuem para a formação da opinião das pessoas, bem como constituem um objeto de consumo, uma experiência individual cotidiana, um sistema de mediação cultural e de agregação social, além de tantas outras funções (WOLF, 2003) ${ }^{2}$.

Para o linguista Noam Chomsky, desviar a atenção da sociedade representa estratégia de manipulação da opinião pública, e sempre de acordo com os interesses das grandes corporações. Chomsky elaborou uma lista contendo "as 10 estratégias de manipulação midiática", das quais ao menos duas ilustram e ratificam as questões aqui apresentadas.

A saber, a estratégia da Distração:

O elemento primordial do controle social é a estratégia da distração, que consiste em desviar a atenção do público dos problemas importantes e das mudanças decididas pelas elites políticas e econômicas, mediante a técnica do dilúvio ou inundações de contínuas distrações e de informações insignificantes. A estratégia da distração é igualmente indispensável para impedir ao público de interessar-se pelos conhecimentos essenciais, na área da ciência, da economia, da psicologia, da neurobiologia e da cibernética.

\footnotetext{
${ }^{2} \mathrm{~A}$ obra Teorias da comunicação de massa, Wolf (2003) discute de maneira detalhada as dife-
} rentes teorias da comunicação social e a evolução destes estudos no cenário social.

Movimento, Porto Alegre, v. 20, n. 2, p. 775-798, abr./jun. de 2014. 
A estratégia da distração é aqui percebida na mudança de foco promovida pela mídia com relação ao consumo de drogas ilícitas em detrimento das lícitas. Tal constatação não significa supor que as questões que envolvem substâncias ilícitas representem problema sem importância, divulgado para distração, mas aponta a necessidade de propagação dos impactos negativos promovidos pelas substâncias lícitas, tão prejudiciais quanto às ilícitas.

A outra estratégia apresentada por Chomsky (2013) é a da Emoção. $\mathrm{O}$ autor aponta: "utilizar o aspecto emocional muito mais do que a reflexão":

Fazer uso do aspecto emocional é uma técnica clássica para causar um curto- circuito na análise racional, e por fim ao sentido crítico dos indivíduos. Além do mais, a utilização do registro emocional permite abrir a porta de acesso ao inconsciente para implantar ou enxertar idéias, desejos, medos e temores, compulsões, ou induzir comportamentos.

Os alardes da mídia que costumam formar a opinião pública ressaltam sempre mais as questões afetas ao ilícito, reforçando estigmas sobre tais usuários, ao mesmo tempo em que amenizam notícias referentes ao consumo de substâncias lícitas, especialmente a cerveja, omitem as consequências negativas nos noticiários e naturalizam o seu uso por meio de peças publicitárias bastante convincentes e com intenso argumento de apelo emocional.

Há também um abuso de imagens que vinculam ídolos do futebol às marcas de cerveja, o que promove, com base em um apelo emocional, uma aproximação entre futebol e consumo de cervejas que beira a naturalidade. Esse apelo à emoção do telespectador é promovido pela identificação com o ídolo esportivo, com o time preferido, por meio da propalação de cenas das arquibancadas lotadas, de torcedores fanáticos, ou dos preparativos para assistir ao jogo pela $\mathrm{TV}$, entre outros contextos referentes ao futebol.

Movimento, Porto Alegre, v. 20, n. 2, p. 775-798, abr.jun. de 2014. 
Em pesquisa sobre as bebidas alcoólicas e os meios de comunicação, Pinsky e Silva (1995, p. 117) e Pinsky e Jundi (2008, p. 362) $)^{3}$ avaliam inúmeros estudos sobre a relação da publicidade e as bebidas e por fim ressaltam: "'[...] as imagens do álcool na mídia parecem ter o efeito de tornar cotidiano, banalizar e legitimar o consumo de bebidas alcoólicas".

Os autores também destacam que estudos econométricos mais recentes consideram que a redução e/ou banimento de publicidade teria efeito na diminuição do consumo de álcool.

Se as evidências científicas sobre possíveis influências das propagandas para o aumento do consumo encontram resistências, considerar o seu inverso - a ausência dessa publicidade - sinaliza, em alguns casos, a diminuição do consumo. Essa afirmação advém das experiências que o Brasil vem colhendo com a política de restrição da publicidade do tabaco.

A Convenção-Quadro para o Controle do Tabaco (CQCT Framework Convention on Tobacco Control) refere-se ao tratado internacional sobre a temática do tabagismo, cujo objetivo final está na tentativa de aumentar os padrões de saúde mundiais. Proposta pela Organização Mundial da Saúde (OMS) em 1999, entrou em vigor no Brasil no ano de 2005, transformando-se num marco histórico na saúde pública.

[...] aderir ao tratado significa um compromisso internacional entre os países que a ratificaram em implantar medidas restritivas de controle dos produtos de tabaco e seus derivados. Afirmam que a implementação eficaz de políticas de controle do tabaco no Brasil trouxe uma redução substancial nas taxas de fumo no país, de relatados $34 \%$ em 1989 para $15 \%$ em 2008 (PANTANI; PINSKY; MONTEIRO, 2011 p. 7).

3 A pesquisa "O impacto da publicidade de bebidas alcoólicas sobre o consumo entre jovens: revisão da literatura internacional", desenvolvida por Pinsky e Jundi (2008), analisou inúmeros estudos sobre propaganda de bebidas e suas interferências sobre o consumo. $\mathrm{O}$ estudo aponta algumas pesquisas longitudinais cujos resultados apontam uma relação causal entre exposição à publicidade de bebidas e o aumento do consumo, especialmente entre os jovens.

Movimento, Porto Alegre, v. 20, n. 2, p. 775-798, abr./jun. de 2014. 
A diminuição do percentual de fumantes continua em declínio no país, ao passo que o consumo de bebidas tem aumentado, especialmente com relação ao beber excessivo.

Desde a implementação das primeiras políticas de restrições à publicidade do tabaco, o Brasil vem alcançando resultados positivos acerca da diminuição do número de fumantes, estabelecendo uma relação direta entre políticas de restrição à publicidade do tabaco e a consequente diminuição do consumo.

A respeito da publicidade que envolve a indústria do álcool, Laranjeira e Romano (2004, p. 74) alertam que:

O marketing do álcool é agora parte de uma indústria global, onde as grandes corporações dão as cartas do jogo tanto nos países industrializados quanto nos novos mercados dos países em desenvolvimento. As estratégias utilizadas para promover as bebidas alcoólicas fazem uso da televisão, do rádio, da mídia impressa, da internet e de promoções nos pontos de venda. E nichos específicos de mercado são desenvolvidos a partir da associação de determinada marca com esportes, estilos de vida e outras artimanhas destinadas a fisgar o consumidor pela via da identificação. Estudos demonstram, de forma consistente, que tais estratégias de promoção do álcool apresentam conseqüências à saúde pública. Tais evidências são fortes o bastante para tirar o Estado de seu papel omisso para, a bem do interesse público, regular a promoção do álcool, em vez de deixar que a indústria e a mídia exerçam sua "auto-regulação".

Ainda, vale citar que Pinsky e Jundi (2008, p. 370) alertam para o fato de que, ao patrocinar certos eventos (concertos de música, atividades esportivas etc.), a propaganda de cerveja mira especialmente a população jovem, passando a mensagem de que "o álcool é parte boa da vida". As autoras destacam as influências exercidas sobre hábitos de consumo:

Seja pela intensidade e freqüência com que bombardeia o potencial ou atual consumidor, tornando-se quase onipresente, seja pelos efeitos

Movimento, Porto Alegre, v. 20, n. 2, p. 775-798, abr.jun. de 2014. 
neurocomportamentais conseqüentes à sua interferência nos circuitos emocionais, o certo é que a publicidade de bebidas alcoólicas é um dos importantes fatores influenciadores dos hábitos de consumo de álcool da população, em particular entre os mais jovens.

No entanto, discutir as possíveis interferências da mídia nos modos de escolha das pessoas requer um debate mais aprofundado que considere as diferentes correntes teóricas relativas aos impactos da comunicação sobre a tomada de decisão dos indivíduos, assunto que demandaria aqui mais espaço. Contudo, é necessário considerar os distintos modos com que a comunicação pode atingir o ouvinte, tanto na forma de notícia ou de propaganda, sem com isso conceber o expectador como um receptor passivo e acrítico.

Se considerarmos as implicações da Lei Geral da Copa sobre a publicidade de cerveja, teremos não apenas um Estado omisso sobre a regulamentação da propaganda de bebidas, mas também um Estado participante dessa situação quando acata as exigências da FIFA e as legitima.

Falar em políticas do álcool, ao contrário do que se imagina, não é falar em proibição total, mas em regulamentação de distribuição, publicidade e venda do produto, entre outras iniciativas.

Ao discutir a complexa relação entre drogas e violência, Minayo e Deslandes (1998) também destacam as dificuldades teóricas e práticas de estudos, suas delimitações, e apontam para um debate necessário no campo da saúde pública e das políticas sociais.

No entanto, há consenso entre pesquisadores do tema acerca das consequências sociais e impactos negativos do uso de álcool, conforme afirmam Meloni e Laranjeira (2004, p. 18):

[...] as consequiências sociais do uso do álcool colocam esse produto, no mínimo, como um fator adicional ou mediador entre outros que contribuem para a ocorrência de determinado problema, conclusão similar àquela válida para problemas de saúde [...] alguns de seus efeitos

Movimento, Porto Alegre, v. 20, n. 2, p. 775-798, abr.jun. de 2014. 
danosos à saúde podem resultar de um episódio único de consumo excessivo, mesmo que a pessoa não beba com freqüência.

Levando-se em conta que os problemas de saúde pública advindos do consumo de álcool no país são maiores, mais intensos e dispendiosos que aqueles provocados por drogas ilícitas, em 2004 tornou-se público o documento "Consenso Brasileiro sobre Políticas do Álcool”, desenvolvido por estudiosos do tema.

Tratar das políticas do álcool pode suscitar, num primeiro momento, lembranças de insucessos que marcaram a história, impulsionados por experiências de total proibição que ocorreram em alguns países no início do século passado. Estados Unidos, Canadá, Noruega, Islândia, Finlândia e Rússia proibiram a produção, transporte e a venda de bebidas alcoólicas a partir de 1914. Mais recentemente houve a "Tolerância Zero", implantada no governo americano de Reagan e que também não resultou em respostas positivas por parte da sociedade, o resultado da intolerância foi o aumento do numero de usuários de drogas e uma política fracassada.

Tais ponderações significam, na atualidade, iniciativas voltadas para a regulamentação de publicidade, não somente aquela transmitida na televisão, mas também as referentes a patrocínios de eventos de lazer, o controle da bebida na condução de veículos, bem como fiscalização de pontos de venda. Enfim, diferentemente daqueles tempos de imposição e proibição, as políticas do álcool dos dias atuais se concretizam em direção a algumas regulamentações em prol da saúde pública. De acordo com Laranjeira e Romano (2004, p. 68), “enxergar as políticas do álcool através da perspectiva restrita da proibição total, entretanto, é negligenciar o fato de que muitas políticas elaboradas durante o século passado incrementaram e respeitaram o direito de beber com moderação".

Assim, não se trata de uma "Lei Seca" ou de um cerceamento do direito de beber, mas sim de compreender a necessidade de políticas reguladoras da publicidade - que aumenta em volume e agressividade os argumentos para o consumo à medida que

Movimento, Porto Alegre, v. 20, n. 2, p. 775-798, abr.jun. de 2014. 
se aproxima a Copa do Mundo de 2014 -, com destaque para a necessidade de se dissociar o consumo de cerveja do futebol.

A luta por políticas do álcool vem sendo travada já há alguns anos. No ano de 2003, por iniciativa da Unidade de Pesquisa em Álcool e Drogas (UNIAD), do departamento de Psiquiatria da Universidade Federal de São Paulo (UNIFESP) e do Conselho Regional de Medicina de São Paulo (CREMESP), foi criada a Aliança Cidadã pelo Controle do Álcool (ACCA), que orquestrou o Movimento Propaganda Sem Bebida.

Segundo Laranjeira, o surgimento desse movimento é decorrente da preocupação com a questão da ausência de efetivas políticas públicas para o controle do álcool no Brasil, reunindo vários segmentos da sociedade civil, como igrejas, universidades, serviços de saúde, entidades de defesa do consumidor, entidades médicas, conselhos profissionais, sindicatos, organizações não governamentais (ONGs), grupos de apoio e mútua ajuda, entidades de defesa de portadores de patologias, entre outras. Uma das metas da Aliança Cidadã é a aprovação de legislação que limite a publicidade de álcool nos meios de comunicação e em eventos esportivos, culturais e sociais, semelhante à legislação atual que restringe as propagandas de cigarro. Atualmente, tais esforços se concentram na aprovação integral de um projeto de lei aprovado na Câmara, PLC n. 35/2000, ainda em tramitação, porém bastante enfraquecida pelos lobbies da indústria do álcool.

A complexidade da temática aqui abordada sugere a necessidade de debates que envolvam os campos da saúde publica e das ciências políticas subsidiando os avanços nos diferentes setores da sociedade que exigem intervenções orquestradas do governo com o saber produzido na academia, muito mais que com os interesses econômicos de lobistas e grandes corporações.

\section{Considerações finAIS}

Discutir os impactos e legados dos megaeventos ultrapassa os limites do tangível, do material representado pelas construções

Movimento, Porto Alegre, v. 20, n. 2, p. 775-798, abr.jun. de 2014. 
esportivas, e exige um olhar mais atento aos aspectos intangíveis, cujas consequências interferem diretamente sobre as políticas de saúde pública, políticas de prevenção ao uso de drogas e nos esforços para a diminuição da violência nos estádios.

A imposição da FIFA acerca do comércio de bebidas não somente desautoriza leis, municipais e estaduais, relativas à proibição da venda e consumo de bebidas nos estádios, mas também oportuniza a flexibilização de normas internas, ratificando um estado de exceção que suspende a autoridade do país e desconsidera os avanços e conquistas.

Ao preterir todos os esforços até então reunidos para a reversão do panorama referente ao consumo de bebidas no país, essa imposição subestima não somente a história de uma nação, mas também as conquistas de grupos de trabalho e, principalmente, os efeitos negativos do álcool sobre a população, pois este foi elevado ao patamar de produto comum. Ao promulgar a Lei Geral da Copa, na qual estão obedecidas as exigências da FIFA, o Estado brasileiro contribui para anunciar e promover o álcool como se fosse uma mercadoria qualquer ou uma bebida inofensiva.

Entre os fatores que justificam tal postura, reforçada pela contradição da mídia televisiva, está o fato de serem as cervejarias, a nacional e a internacional, os principais patrocinadores da Copa do Mundo de Futebol de 2014, da seleção brasileira de futebol e dos programas televisivos, com destaque para os programas esportivos.

A imagem da bebida fortemente vinculada ao futebol alimenta a falsa impressão de que o lícito é inofensivo e saudável, e somente o ilícito é passível de consequências desastrosas, tanto no nível individual quanto social.

No Brasil, o álcool não é visto como uma droga, ainda que as reações provocadas pela substância no organismo humano e na sociedade sejam nocivas. $\mathrm{O}$ fato de ser lícito o coloca em uma falsa categoria de bebida inocente, conferindo uma permissividade para o consumo, incansavelmente propagada e legitimada pela mídia.

Movimento, Porto Alegre, v. 20, n. 2, p. 775-798, abr.jun. de 2014. 
O momento atual e os números referentes ao consumo de bebidas apontam muito mais para a necessidade de se buscar soluções para amenizar os problemas e consequências desse consumo - tomando-se por base a implementação de medidas de prevenção e regulamentação da publicidade e venda - do que de campanhas de incentivo ao consumo fortalecido pelo aval do Estado.

Se o interesse das grandes corporações é aumentar o lucro, e o faz por meio da publicidade e patrocínio de eventos (esportivos e artísticos) - para a qual a Lei Geral da Copa e a FIFA pedem passagem -, os resultados servirão de legado positivo para as cervejarias por conta do aumento de consumo e consumidores no Brasil.

Para as grandes corporações, o lucro fica garantido; e para as políticas do álcool, de saúde, de prevenção, restará buscar forças para recomeçar se o provisório desse estado de exceção não for transformado em permanente.

World cup and beer: intangible impacts of a mega evento Abstract: The realization of mega sporting events in Brazil has motivated changes in various social contexts, and promote changes in legislation. FIFA requirements disregard of the political achievements of alcohol and about violence in stadiums, strengthening the link between beer and football. Considering the negative consequences of granting the sale and consumption of beer in stadiums and advertising of beer involving the World Cup, this article discussed intangible impacts of the 2014 World Cup. Signals of increasing the number of beer drinkers as a result of the General Law of the Cup, highlighting the negative aspects to society.

Keywords: mega, world cup, beer

Movimento, Porto Alegre, v. 20, n. 2, p. 775-798, abr./jun. de 2014. 


\section{Copa del Mundo y cerveza: impactos intangibles de un} mega evento

Resumen: La realización de megaeventos deportivos en Brasil ha motivado cambios en los diferentes contextos sociales, y promove cambios en la legislación. Los requisitos de la Federación Internacional de Fútbol Asociado (FIFA) el desprecio de los logros políticos de alcohol y la violencia en los estadios, estrechando el vínculo entre la cerveza y el fútbol. Teniendo en cuenta las consecuencias negativas de la concesión de la venta y el consumo de cerveza en los estadios y la publicidad de la cerveza que implica la Copa del Mundo, este artículo describe los impactos intangibles de la Copa del Mundo de 2014. Señales el aumento del número de bebedores de cerveza, como resultado de la Ley General de la Copa, destacando los aspectos negativos para la sociedad.

Palabras clave: mega, mundial, cerveza.

\section{REFERÊNCIAS}

ALIANÇA CIDADÃ PELO CONTROLE DE ÁLCOOL. Novos caminhos. Disponível em: <http://www.uniad.org.br/asp/novos_caminhos_acca.asp>. Acesso em: set. 2013.

AGAMBEN, G. Estado de exceção. Tradução de Iraci D. Poleti. São Paulo: Boitempo, 2004.

BRASIL. Lei n. 8.069, de 13 de julho de 1990. Dispõe sobre o Estatuto da Criança e do Adolescente e dá outras providências. 1990. Seção II, Artigo 243. Disponível em: <www.planalto.gov.br/ccivil_03/Leis)L8069.htm>. Acesso em: 12 mar. 2013.

BRASIL. Lei n. 10.671, de 15 de maio de 2003. Dispõe sobre o Estatuto de Defesa do Torcedor e dá outras providências. Disponível em: <http://presidencia.gov.br/ CCIVIL/LEIS/2003/L10.671.htm>. Acesso em: 12 mar. 2013.

BRASIL. Projeto de Lei n. 2.330 de setembro de 2011. Dispõe sobre as medidas relativas à Copa das Confederações FIFA de 2013 e à Copa do Mundo FIFA de 2014, que serão realizadas no Brasil. Disponível em: <http://www.camara.gov.br/ sileg/default.asp>. Acesso em: 12 mar. 2013.

BERTOLO, M. A.; ROMERA, L. A. Cerveja e publicidade: uma estreita relação entre lazer e consumo. Licere, Belo Horizonte, v. 14, n. 2, jun. 2011.

CHOMSKY, N. Chomsky e as 10 estratégias de manipulação midiática. Disponível em: <http://www.institutojoaogoulart.org.br/>. Acesso em: 14 mar. 2013.

DA COSTA, L. P. (Ed.). Legados de megaeventos esportivos. Brasília: Ministério do Esporte, 2008.

Movimento, Porto Alegre, v. 20, n. 2, p. 775-798, abr.jun. de 2014. 
HOLLANDA, B. B. B. O clube como vontade e representação: o jornalismo esportivo e a formação das torcidas organizadas de futebol do Rio de Janeiro. Rio de Janeiro: 7Letras, 2009.

INTANGÍVEL. In: MICHAELIS Dicionário. Disponível em: <http://michaelis.uol.com.br/moderno/portugues/index. php? Iingua $=$ portugues - portugues \& palavra=intang $\%$ EDvel $\% 20$ $\& C P=984522 \&$ typeToSearchRadio=exactly\&pagRadio=50>. Acesso em: 13 abr. 2013.

KERR-CORREA, F. High risk alcohol use in Brazil college students (UNESP): preliminary data from a preventive study. In: ANUAL ALCOHOL EPIDEMIOLY SIMPOSIUM, 28., 2002, Paris. Paris: KBS, 2002.

LARANJEIRA, R.; ROMANO, M. Consenso brasileiro sobre políticas públicas do álcool. Revista Brasileira de Psiquiatria, São Paulo, 2004. Disponível em: <http:// www.scielo.br/scielo.php?script=sci_arttext\&pid=S1516-4462004000500017\&lng= en\&nrm=iso>. Acesso em: 15 mar. 2013.

MARTINS, R. A. Uso de álcool, intervenção breve e julgamento sócio-moral em adolescentes que bebem excessivamente. 2006. Tese (Livre-Docência em Psicologia da Educação) - Instituto de Biociências, Letras e Ciências Exatas, Universidade Estadual Paulista, 2006.

MASCARENHAS, F. Megaeventos esportivos: alerta de tsunami. Movimento, Porto Alegre, v. 18, n. 1, p. 39-67, jan./mar. 2012.

MELONI, J. N.; LARANJEIRA, R. Custo social e de saúde do consumo do álcool. Revista Brasileira de Psiquiatria, São Paulo, 2004. Disponível em:<http://www.scielo.br/scielo.php?script=sci_arttext\&pid=S1516$44462004000500003 \&$ Ing=en\&nrm=iso>. Acesso em: 17 mar. 2013.

MENDOZA-SASSI, R. A.; BÉRIA, J. U. Prevalence of alcohol use desorders and associated factors: a population based using AUDIT in southerm Brazil. Addiction, [S.I.], n. 98, p. 799-804, 2003.

MINAYO, M. C. S.; DESLANDES, S. F. A complexidade das relações entre drogas, álcool e violência. Caderno de Saúde Pública, Rio de Janeiro, v. 14, n. 1, p. 3542, jan. 1998.

NOTO, A. R.; BAUER, J. As drogas e os meios de comunicação. Texto adaptado do original do Curso de Capacitação para Conselheiros e lideranças Comunitárias, realizado pela SENAD em 2011. Disponível em: <http://www.forumsobredrogas. org/wp-content/uploads/2013/05/XVII.-As-drogas-e-os-meios-de-comunicacao. pdf>. Acesso em: set. 2013.

PANTANI, D.; PINSKY, I.; MONTEIRO, A. Publicidade de tabaco no ponto de venda. São Paulo: Ed. do Autor, 2011.

PERNAMBUCO. (Estado). Lei n. 13.748/2009, de 16 de dezembro de 2009. Disponível em: <http://www.sefaz.pe.gov.br/flexpub/versao1/filesdirectory/ sessions4469.pdf>. Acesso em: 16 mar. 2013.

Movimento, Porto Alegre, v. 20, n. 2, p. 775-798, abr./jun. de 2014. 
Copa do Mundo e cerveja: impactos intangíveis..

PINSKY, I. Publicidade de bebidas alcoólicas e os jovens. São Paulo: FAPESP, 2009.

PINSKY, I; JUNDI, S. O impacto da publicidade de bebidas alcoólicas sobre o consumo entre jovens: revisão da literatura internacional. Revista Brasileira de Psiquiatra, São Paulo, v. 30, n. 4, p. 362-374, nov. 2008.

PINSKY, I.; SILVA, M.T.A. As bebidas alcoólicas e os meios de comunicação: revisão da literatura. Revista ABP-APAL, São Paulo, v. 17, n. 3, p. 115-121, 1995.

PREUSS, H. Aspectos sociais dos megaeventos esportivos. In: RUBIO, K. (Org.). Megaeventos esportivos, legado e responsabilidade social. São Paulo: Casa do Psicólogo, 2007. p. 13-35.

PRONI, M. W. Observações sobre impactos econômicos esperados dos jogos olímpicos de 2016. Motrivivência, Florianópolis, v. 21, n. 32-33, p. 49-70, jun./ dez. 2009.

RAEDER, S. Jogos e cidades: ordenamento territorial em sedes de megaeventos esportivos. Brasília: Ministério do Esporte, 2010.

REIS, H. H. B. Lei Geral da Copa, álcool e o processo de criação da legislação sobre violência. Movimento, Porto Alegre, v. 18, n. 1, p. 69-99, jan./mar. 2012.

REPPOLD FILHO, A. R. A regeneração urbana e direitos do cidadão: o caso dos Jogos Olímpicos de Atlanta 1996. In: DACOSTA, L. P. (Ed.). Legados de megaeventos esportivos. Brasília: Ministério do Esporte, 2008. p. 175-188.

RIO DE JANEIRO. Federação de Futebol. Presidência. Resolução n. 1212013, de 11 de março de 2013. Disponível em: <http://www.fferj.com.br/_arquivos/ documentos/36f6b55d4c0c5517808b6715b37bce7c.pdf>. Acesso em: 14 mar. 2013.

ROLNIK, R. Entrevista. Disponível em: <http://ludopedio.com.br/rc/indez.php/ entrevistas/artigo/894>. Acesso em: 2 mar. 2013.

ROMERA, L. A. Juventude, lazer e uso abusivo de álcool. 123f. Tese (Doutorado) -Faculdade de Educação Física, Universidade de Campinas, Campinas, 2008.

ROMERA, L. A.; REIS, H. H. B. Uso de álcool, futebol e torcedores jovens. Motriz, Rio Claro, v. 15, n. 3, p. 541-551, 2009.

RUBIO, K. (Org.). Megaeventos esportivos, legado e responsabilidade social. São Paulo: Casa do Psicólogo, 2007.

SAMPAIO, M. A. Com leis próprias, megaeventos criam estado de exceção. Disponível em: <http://www.apublica.org/2013/01/copa-do-mundo-olimpiadas-leisestado-de-excecao/>. Acesso em: 12 abr. 2013.

SÃO PAULO. (Cidade). Lei municipal n. 14.726, de 15 de maio de 2008. Estabelece normas para repressão a comercialização e ao consumo de bebidas alcoólicas nos estádios de futebol e conjuntos poliesportivos no município de São Paulo, em eventos esportivos profissionais e dá outras providências. Disponível

Movimento, Porto Alegre, v. 20, n. 2, p. 775-798, abr.jun. de 2014. 
em: $\quad$ <http://camaramunicipalsp.qaplaweb.com.br/iah/fulltext/leis/L14726.pdf>. Acesso em: 10 mar. de 2012.

São Paulo. (Cidade). Lei n. 9.470/96, de 27 de dezembro de 1996. Dispõe sobre a manutenção de toda a lotação com lugares numerados nos estádios de futebol, ginásio de esporte e estabelecimentos congêneres. Disponível em: <http://governosp.jusbrasil.com.br/legislacao/172061/lei-9470-96>. Acesso em: 2 out. 2013.

BRASIL. Ministério da Justiça. Secretaria Nacional de Política sobre Drogas. Política sobre drogas: prevenção e tratamento. Disponível em: <http://portal.mj.gov.br/senad/data/Pages/ MJCD569DD3ITEMIDA076837802FB4A13B1A93DFC293350BEPTBRNN.htm>. Acesso em: 10 mar. 2013.

TAVARES, O. G. Megaeventos esportivos. Movimento, Porto Alegre, v. 17, n. 3, p. 11-35, jul./set. 2011.

VIEIRA, M. V. MP-RJ: liberação de bebidas fere Estatuto do Torcedor. Disponível em: < http://www.uniad.org.br/desenvolvimento/index.php/blogs/dependenciaquimica/18124-mp-rj-liberacao-de-bebidas-fere-estatuto-do-torcedor $>$. Acesso em: 15 mar. 2013.

WOLF, M. Teorias das comunicações de massa. São Paulo: Martins Fontes, 2003.

Endereço para correspondência:

Rua Laurentino Proença Filho, 300 ap 501 B Jd Penha

Vitoria ES CEP 29060440

Recebido em: 08.05.2013

Aprovado em: 26.02.2014

Movimento, Porto Alegre, v. 20, n. 2, p. 775-798, abr./jun. de 2014. 